\title{
Educação parental e pedagogia social: avaliação de uma proposta de intervenção
}

\author{
Parenting education and social pedagogy: evaluation an intervention proposal
}

Educación parental y pedagogía social: evaluatión de una propuesta de intervención

\author{
NARJARA MENDES GARCIA* \\ MARIA ANGELA MATTAR YUNES** \\ ANA MARIA TOMÁS ALMEIDA***
}

\begin{abstract}
$\diamond$
RESUMO

Intervenções em educação parental são raras no Brasil e situam-se no campo da pedagogia social. O artigo apresenta a análise de uma proposta educativa com famílias para a promoção da parentalidade responsável. Para tanto, foi realizado, em contexto brasileiro, um programa de educação parental europeu intitulado "Crescer Felizes em Família". Investigou-se a dinâmica de funcionamento, o papel dos facilitadores, a satisfação e a eficácia da intervenção na perspectiva da equipe de educadores e das famílias participantes. Os resultados apontaram a necessidade de garantir a adesão das famílias e de ajustes do programa para aplicação em contexto brasileiro. Os elementos que mais contribuíram para a condução do programa de educação parental com sucesso no Brasil foram: a qualidade da mediação pedagógica dos educadores com as famílias, a abordagem sistêmica dos conteúdos da proposta educativa e o uso de metodologias da Pedagogia Social, que têm por base o diálogo e o respeito às diferenças individuais e culturais.

Palavras-chave: Pedagogia social. Educação parental. Famílias. Parentalidade. Educadores sociais.
\end{abstract}

\begin{abstract}
Parenting educational interventions are rare in Brazil and relate to the field of social pedagogy. This proposal presents the analysis of a proposal on a family educational program for the promotion of responsible parenting. Therefore, a parenting educational european program was conducted in a Brazilian context entitled "Growing as a Happy Family". It was investigated: the dynamics of operation, the role of the facilitators, the satisfaction/ effectiveness in the view of the team of educators and the participating families. The results indicated a need to guarantee the adherence/ participation of families and some adjustments to the Brazilian context. The elements that mostly contributed to the satisfaction/effectiveness of the parenting educational program in Brazil were the quality of pedagogical mediation of the educators with the families, the systemic approach to the educational proposal content and the use of methodologies of Social Pedagogy that are based on dialogue and respect to the individual and cultural differences. Keywords: Social Pedagogy. Parental education. Families. Parenting. Social educators.
\end{abstract}

\section{RESUMEN}

Intervenciones en educación parental son raras en Brasil y están en el campo de la pedagogía social. El artículo presenta el análisis de una propuesta educativa com familias para promover la pareduentalidad responsable. Por lo tanto, se llevó a cabo en el contexto brasileño, un programa de educación parental europeo titulado "Creciendo Felices en Familia". Investigamos la dinámica de funcionamiento, el papel de facilitadores, la satisfacción y la eficacia de la intervención en opinión del equipo de educadores y familias participantes. Los resultados mostraron la necesidad de garantizar el compromiso de las familias y ajustar la configuración del programa para su uso en el contexto brasileño. Los elementos que más contribuyeron para a la realización del programa de educación con éxito en Brasil fueron: calidad de la enseñanza de los educadores de mediación con las familias, el enfoque sistémico para el contenido de la propuesta educativa y el uso de métodos de pedagogía social que se basan el diálogo y el respeto a las diferencias individuales y culturales.

Palabras clave: Pedagogía social. Educación parental. Familias. Parentalidad. Educadores sociales.

\footnotetext{
* Pedagoga e Doutora em Educação Ambiental. Professora Adjunta do Instituto de Educação na Universidade Federal do Rio Grande - FURG. Professora do Programa de Pós-Graduação em Educação Ambiental - PPGEA/FURG. E-mail: <narjaramg@yahoo.com.br>.

** Psicóloga e Doutora em Psicologia da Educação. Professora permanente no Programa de Pós-Graduação do Centro Universitário La Salle - UniLaSalle Canoas/RS e colaboradora no Programa de Pós-Graduação em Educação Ambiental, FURG. E-mail: <mamyunes@yahoo.com.br>.

***Psicóloga e Doutora em Educação da Infância. Professora permanente no Instituto de Educação. Coordenadora do Programa de Pós-graduação em Intervenção social com crianças, adolescentes e famílias, Universidade do Minho, Portugal. E-mail: <anatalmeida@gmail.com>
} 


\section{INTRODUÇÃO}

A educação parental é um conceito novo e ainda pouco explorado no Brasil; é uma proposta educativa para a promoção da parentalidade responsável e se enquadra no campo das Ciências da Educação e da Pedagogia Social. As estratégias de intervenção em educação parental pressupõem o apoio e a orientação de pais ou de outros cuidadores para a qualidade e exercício da parentalidade nas famílias (HEATH, 2004). No campo das intervenções com famílias, a educação parental apresenta objetivos e metodologias específicos, o que a torna uma modalidade diferente de outras intervenções como a terapia familiar, o aconselhamento e a informação parental (SAMPAIO; CRUZ; CARVALHO, 2011).

As propostas de educação parental se diferenciam das ações de educação familiar, geralmente adotadas nas áreas de educação em saúde e assistência social. Esta se faz presente nas interações promovidas pelo atendimento familiar realizado pelos profissionais que integram a rede de apoio social e através de campanhas educativas promovidas pela mídia. Já a proposta de educação parental é uma ação programada que apresenta como especificidade a mediação e/ou orientação sobre as práticas educativas parentais e sobre a promoção do papel social responsável e protetivo da família na educação de crianças e adolescentes.

É consenso entre os investigadores dessa área que a proposição de programas de educação parental apresenta como intenção a realização de ações de atendimento individual ou grupal que visam a promover a reflexão sobre as práticas dos pais de acordo com as necessidades de desenvolvimento das crianças. Dessa forma, as intervenções com foco na parentalidade centram-se em prevenir os maus-tratos e a negligência contra crianças e jovens e construir estratégias para o bom trato e bemestar nas interações familiares (QUINTANA et al, 2009; QUINTANA; LÓPEZ, 2013). Tais intervenções exigem um estudo diagnóstico do contexto para melhor compreensão das condições e do planejamento adequado que atenda às reais necessidades educativas das famílias.

Essa proposta integra um conjunto de conhecimentos sobre os processos educativos intrafamiliares (relações entre pais e filhos) e extrafamiliares (relações entre a família e a escola; a família e entre outros contextos da rede social) (CHILDONEUROPE, 2007). As ações de educação parental são planejadas, desenvolvidas e avaliadas por educadores sociais capacitados, que atuam como mediadores e orientadores dos grupos familiares no cuidado/educação das crianças.

No que se refere ao lugar da educação na área do trabalho social, a disciplina científica que melhor responde a essas exigências é, de todo, sem margem para dúvida, a pedagogia social. Ela fornece ferramentas teóricas necessárias para uma intervenção no terreno que vise a ajudar a tecer laços sociais e a criar situações de aprendizagem potenciadoras de felicidade, de bem-estar e de autonomia de vida (CARVALHO; BAPTISTA, 2004, p. 60).

No contexto brasileiro ainda são escassas as ações pedagógicas em educação social com foco na parentalidade. Sabe-se da realização de algumas iniciativas realizadas por centros de pesquisa e extensão universitária e políticas públicas regionais, como o Programa Infância Melhor - PIM realizado no Rio Grande do Sul. Muitos países, como Portugal, Espanha e Estados Unidos, já avançaram nessa área de conhecimento e possuem ações e programas sociais direcionados para a educação de pais e/ou responsáveis e servem de exemplo nas discussões sobre proteção da família.

Em Portugal, por exemplo, existe uma diversidade de serviços de apoio familiar que incorporam um número significativo de intervenções e programas realizados com àas famílias (ALMEIDA et al, 2012). Os pesquisadores portugueses realizaram um estudo recente, entre 2007 e 2010, que avaliou a implementação e a eficácia de 56 intervenções de educação parental que, no geral, atenderam 501 sujeitos (ALMEIDA et al., 2012). Foram avaliadas intervenções grupais em espaço comunitário com diferentes formatos e organizações metodológicas.

Os programas de educação parental emergiram nos países europeus a partir de uma orientação da ChildONEurope (www.childONEurope.org), uma organização internacional da União Europeia, que apontou a necessidade de os Estados elaborarem e apresentarem medidas adequadas para prestar assistência aos pais no cumprimento das suas responsabilidades (CHILDONEUROPE, 2007). Foram propostas ações de educação e de aconselhamento parental através de programas parentais para apoiar os pais ou outros membros familiares no exercício da parentalidade. A intenção era direcionar apoio a todas as famílias, independentemente de configuração, organização ou situação legal das mesmas. Dessa forma, evita-se o tratamento preferencial de uma certa "forma" de família em detrimento de outras.

As ações de educação parental são concebidas como medidas de proteção e preservação dos vínculos familiares, e as famílias aparecem como coparticipantes do processo de enfrentamento das situações de risco vivenciadas.

Adopta-se a ideia de que a experiência vivida por cada pai deve ser valorizada numa intervenção desta natureza e deve servir de ponto de partida para a mesma. (...) Assistimos assim a um afastamento da 
ideia mais tradicional associada à escola, veiculada por intervenções que se baseiam exclusivamente em palestras verticais e em avaliação dos conhecimentos, e que reforçam a ideia de inoperância e incompetência dos pais (SAMPAIO; CRUZ; CARVALHO, 2011, p. 26).

A ideia de educação parental no modelo reflexivo em que se promove a preservação dos vínculos familiares e a resiliência parental vem embasando as ações das equipes dos programas sociais na Espanha e em Portugal, há alguns anos. O termo Preservação Familiar se refere às ações que contribuem para manter a criança ou o adolescente em casa, quando os responsáveis pelo seu cuidado, atenção e educação por diversas circunstâncias desistem de suas funções parentais ou usam práticas inadequadas que comprometem ou prejudicam o desenvolvimento pessoal e social do menor, mas sem alcançar a gravidade que justifique uma medida de separação deste da sua família (RODRIGO et al., 2008a). Essas ações implicam a prevenção e a oportunidade para que as famílias, com o apoio adequado, possam cumprir suas funções e assumir as responsabilidades no cuidado e educação das crianças e dos adolescentes, garantindo que estes possam ter um desenvolvimento saudável. $\mathrm{O}$ trabalho de prevenção e resiliência parental tem como enfoque a potencialização dos fatores positivos e das competências dos grupos familiares diante dos riscos para a promoção da parentalidade positiva e protetora. Esta contrapõe as situações de negligência dos cuidados básicos e práticas educativas parentais coercitivas baseadas em punições físicas e violência psicológica para o controle do comportamento infantil.

No Brasil, ainda imperam as políticas de atendimento familiar centradas na medida de proteção diante de situações de risco graves, principalmente quando se trata de famílias em situação de pobreza, que apresentam menor número de recursos, maior fragilidade na rede de apoio social e afetiva, com consequente quadro de vulnerabilidade socioambiental. Implementar políticas preventivas de apoio dirigidas a todas as famílias e que promovam as suas dimensões positivas é fundamental na agenda dos serviços públicos brasileiros. Como apontado anteriormente, no contexto europeu os Estados são responsabilizados e direcionados a apresentar medidas para a eficiência das políticas da parentalidade positiva. Esss políticas apontam para a universalidade das ações de educação parental a fim de que todas as famílias sejam apoiadas no exercício da parentalidade.

No que se refere ao cenário brasileiro, são evidentes as lacunas nas políticas sociais de apoio e de promoção da parentalidade. Diante disso, surgiu o interesse em replicar, no Brasil, um programa de educação parental realizado em contexto europeu. O programa, intitulado
"Crescer Felizes em Família: Apoio Educativo para o Desenvolvimento Infantil" (RODRIGO et al., 2008b), é uma proposta educativa elaborada e desenvolvida amplamente nas escolas e nos centros comunitários, na Espanha, e se enquadra na perspectiva ecológica baseada na teoria de Bronfenbrenner (1996). Nesta, o enfoque está na interação contextual da família e no suporte social para o exercício da parentalidade, não restringindo as influências somente à díade mãe e filho. Esse programa possui estratégias específicas que possibilitam compreender as interações, os discursos e as dinâmicas das experiências parentais e destes com a rede de apoio e seus profissionais.

O presente artigo visa a analisar as particularidades decorrentes da implementação desse programa de educação parental em contexto brasileiro. Para tanto, foram examinadas as especificidades da dinâmica de funcionamento, os facilitadores e os desafios enfrentados na realização do programa, bem como a satisfação e o impacto na percepção das famílias participantes. $\mathrm{Na}$ sequência, apresentam-se as estratégias metodológicas e a discussão sobre os desafios encontrados para a realização do programa no Brasil. Serão destacados os aspectos ecológico-sistêmicos que podem influenciar outras propostas de educação parental em contextos de situação de pobreza e risco social.

\section{MÉTodo}

Tendo em vista os objetivos deste estudo, foi realizado um programa de educação parental no Brasil. O estudo da implementação do programa de educação parental seguiu os princípios pela abordagem teórica de Bronfenbrenner (1979/1996) e metodológica da "Inserção Ecológica" (CECCONELLO; KOLLER, 2004; PRATI et al., 2008) que propõe a inserção dos pesquisadores nos ambientes a serem estudados. O citado modelo teórico explicativo do desenvolvimento humano é composto e compreendido na ótica de quatro dimensões inter-relacionadas: Processo, Pessoa, Contexto e Tempo. Tais núcleos não se constituem em categorias para a coleta e análise de dados, porém são dimensões que possibilitam lançar um "olhar" holístico e sistêmico sobre as influências no desenvolvimento de pessoas e grupos.

Com vistas à inserção dos pesquisadores no ambiente comunitário e à integração com os segmentos da rede de apoio social, foi proposta uma parceria com os profissionais que fazem parte de alguns desses serviços (conselheiros tutelares, representantes de associações de bairro, professores e direção de escolas públicas, equipes das unidades de saúde da família) no município de Rio Grande (RS). Esses profissionais foram os responsáveis pela escolha e pelo encaminhamento das famílias 
participantes. Para isso foi firmado um Termo de Parceria, com uma carta de apresentação do programa e outra de encaminhamento das famílias, em que constavam os motivos da indicação do grupo familiar. $\mathrm{O}$ único critério definido previamente é que seriam famílias em situação de risco (as condições não foram especificadas/ delimitadas pelos pesquisadores), com filhos de até 10 anos de idade. Poderiam participar dos encontros todos os membros do grupo familiar, inclusive as crianças. As famílias encaminhadas pelos profissionais e que aceitaram participar dos encontros assinaram o Termo de Consentimento. Foram realizados reuniões e contatos periódicos com os coordenadores dos serviços sociais para o acompanhamento das atividades do programa e da participação dos grupos familiares.

\section{Coleta e análise dos dados}

As informações sobre a implementação do programa foram coletadas através de diário de campo, recurso utilizado como um instrumento coletivo para o registro por parte da equipe de pesquisadores e executores do programa. E este se mostrou adequado para expressar as percepções integradas sobre a pesquisa. A equipe do programa realizado no Brasil foi composta por um grupo de colaboradores e acadêmicos vinculados ao grupo de pesquisa na universidade (suprimido o nome do grupo e da universidade). Teve a supervisão de professoras investigadoras especialistas na temática do programa, além do apoio de três monitoras (profissionais com experiência no atendimento familiar) e 20 acadêmicos dos cursos de Pedagogia e Psicologia. Ao final de cada encontro, a equipe se reunia e preenchia o diário de campo com seus relatos e avaliações dos discursos e ações dos participantes nas atividades de pesquisa.

Além do diário de campo, foi utilizado o "Questionário de Avaliação da Satisfação e Eficácia do Programa de Formação Parental" (ALMEIDA et al., 2008) como instrumento para avaliação do programa pelas famílias participantes. Esse questionário era composto por cinco questões abertas que visavam à identificação dos participantes e pela indicação do que foi mais útil no programa, do que gostou mais e menos, dos aspectos a serem melhorados e das necessidades de apoio que ainda sentiam no desempenho da sua função parental. Foi aplicado no último encontro do programa. A análise da satisfação pessoal em um programa social é um critério avaliativo importante. De acordo com Serrano (2008), "é evidente que o sucesso de um projeto está relacionado diretamente com o nível de satisfação que as pessoas implicadas no mesmo possam obter" (p. 87).

Os dados coletados através do diário de campo e do questionário de avaliação do programa foram analisados qualitativamente. Para isso, foram seguidos os princípios e passos propostos da Teoria Fundamentada nos Dados (CHARMAZ, 2009), que possibilita a análise dos dados de modo que as categorias e subcategorias surjam a partir das anotações do diário de campo e dos insights dos pesquisadores. Assim, as teorias podem ser construídas a partir do processo de pesquisar.

Após a leitura atenta do diário de campo e dos questionários preenchidos, foram selecionadas as falas/frases significativas para a análise e definição de categorias. As categorias se apresentaram de forma ampla como as principais temáticas que emergiram na análise dos diários. Além disso, nessa etapa, as falas/frases foram analisadas de forma a detalhar mais as categorias e possibilitar a identificação de subcategorias. Nesse sentido, a definição de subcategorias mostrou-se relevante para delimitar, de forma mais específica, as abordagens das temáticas que aparecem nos relatos dos participantes.

\section{RESULTADOS}

A partir da análise dos dados obtidos no estudo realizado mediante a aplicação do programa de educação parental em contexto brasileiro, foi possível extrair três grandes categorias que nortearam a organização dos resultados deste estudo:

\section{Dinâmica de funcionamento do programa}

O programa "Crescer Felizes em Família: Apoio Educativo para o Desenvolvimento Infantil", de autoria de pesquisadores espanhóis (RODRIGO et al., 2008b), foi aplicado na versão reduzida e adaptado de acordo com os condicionantes contextuais. As principais adaptações realizadas estão relacionadas aos seguintes itens: idioma, linguagem, adequação do material impresso, tempo de realização das sessões e número de atividades aplicadas em cada sessão.

Esse programa foi desenvolvido no período de cinco meses. Os encontros em grupo aconteceram semanalmente, em três locais, em bairros do município do Rio Grande (RS): uma escola, uma ONG e um centro comunitário. A duração para cada encontro foi de duas horas. No final de cada encontro havia uma reunião da equipe de 30 minutos para a avaliação do encontro e preenchimento do diário de campo.

\section{a) Modelo experiencial e os princípios do Programa "Crescer Felizes em Família"}

A descrição do programa de educação parental "Crescer Felizes em Família" está em um manual com as instruções direcionadas aos mediadores/ dinamizadores. Todo o material original em espanhol foi traduzido e adaptado para a língua portuguesa. Os conteúdos 
abordados centraram-se nos aspectos educativos, relacionais e experenciais da convivência entre pais e filhos, tendo como finalidade o desenvolvimento de competências pessoais e sociais. Estes foram distribuídos em cinco módulos temáticos que se dividiam em 12 sessões. Os módulos temáticos incluem atividades que contribuem para o diálogo de saberes e reflexão sobre as práticas educativas parentais. São divididos em sessões e cada sessão representou um encontro de duas horas de duração. Cada sessão apresentou um tema, objetivos, atividades específicas e o compromisso pessoal a ser cumprido semanalmente pelas famílias participante da atividade.

No Módulo 1, Desenvolvimento do vínculo afetivo, foram abordados os diferentes tipos de apego entre pais/ mães e filhos/as e como se estabelecem essas relações nas primeiras etapas da vida das crianças. Para isso, foram discutidos os papéis parentais, a relação afetiva com a criança, as demandas dos filhos e as respostas a estas. No Módulo 2, Conhecendo os filhos: necessidades da criança e desenvolvimento infantil, foram propostas atividades para a reflexão sobre como são e o que necessitam as crianças, com enfoque sobre as infâncias, as características individuais, as expectativas dos pais e os comportamentos e desenvolvimento infantil. O Módulo 3. Aprender a lidar com o comportamento infantil, possibilitou discussões sobre os comportamentos das crianças e sobre o papel dos pais na educação dos filhos, tendo em vista a necessidade de relacionar a adequação dos comportamentos das crianças às normas sociais, às expectativas parentais, aos desejos dessas crianças ao bem-estar e ao desenvolvimento infantil. No Módulo 4, A primeira relação com a escola, foram propostas atividades para a reflexão sobre o início da escolarização das crianças, com enfoque sobre as relações familiares que contribuem para atitudes positivas nessa etapa da vida infantil e sobre as interações entre família e escola. Já no Módulo 5, Educar: uma tarefa solitária?, os participantes tiveram a possibilidade de reconhecer a importância das redes de apoio para o desenvolvimento do grupo familiar, conhecendo os recursos e possibilidades a partir da interação com os serviços de apoio social.

A metodologia segue o modelo experiencial com base em atividades abordadas por meio de histórias fictícias e posteriores questões para o debate, nas quais se oferece a chance de aprofundar e explorar causas e a sua relação com as consequências de diferentes práticas parentais. Após, estabelecem-se compromissos a serem assumidos pela família, terminando com uma atividade que permite visualizar e dar relevo aos tópicos principais da sessão. Como exemplo, a atividade "como atuo diante dos caprichos dos meus filhos" proporcionou uma análise por parte dos participantes sobre como os pais reagem diante de situações como as explicitadas nessa atividade. "Na segunda atividade: 'Como atuo diante dos caprichos dos meus filhos', Tânia ${ }^{1}$ contribuiu dizendo que não pode deixar as crianças chorando. Ângela falou que seu marido estraga as crianças porque ele sempre acaba fazendo as vontades delas e diz que essa atitude dele está errada e ele responde a ela dizendo que o dinheiro é dele. Sandra disse que, quando tem dinheiro, ela compra e, se não tem, não compra, e seus filhos entendem" (diário do grupo de pesquisa). Depois do relato de experiências, os educadores e os participantes discutiam as consequências dessas práticas parentais e as possíveis reações das crianças. Essa atividade proporcionou ainda outro debate importante relacionado à infância e ao consumo na atualidade.

Outro exemplo é a atividade "O que as crianças necessitam?" (Sessão 1 do Módulo 2), que propiciou um olhar atento e a reflexão das famílias participantes sobre as necessidades das crianças. "Na atividade sobre as necessidades, a Jaqueline classificou as físicas como mais importantes que as emocionais e de aprendizagem. No entanto, antes da classificação, ela colocou que todas são importantes. Ela classificou por fases, deixando claro que ela considera como mais importantes as necessidades das crianças menores do que as das maiores" (diário do grupo de pesquisa). A partir da discussão ficou evidente para as famílias que todas as necessidades estão interrelacionadas e são fundamentais para o desenvolvimento integral da criança, independentemente da faixa etária.

$\mathrm{Na}$ perspectiva do modelo experiencial, o fortalecimento das competências parentais e a proposição de estratégias e práticas parentais são construídas a partir da partilha de experiências entre as famílias participantes. Nas atividades realizadas no programa aplicado em contexto brasileiro, as famílias tiveram a possibilidade de compreender melhor a sua função parental, conhecer as necessidades das crianças e escolher as estratégias protetivas (sem o uso da violência) mais adequadas para cada situação vivenciada.

\section{b) Perfil das famílias participantes}

Participaram 59 famílias indicadas pelos profissionais dos serviços de apoio social. Os profissionais referidos integravam três conselhos tutelares, quatro escolas públicas (duas municipais e duas estaduais), duas ONGs e seis unidades do Programa Saúde da Família. Essas famílias participaram do primeiro encontro do programa e, destas, 35 aderiram à proposta.

Os motivos apontados com maior frequência pelos profissionais como indicadores para o encaminhamento das famílias para o programa de educação parental foram: a configuração familiar não nuclear, a negligência

\footnotetext{
1 Os nomes dos participantes do programa são fictícios.
} 
materna, a dependência química, as dificuldades financeiras e as dificuldades no desempenho da função parental, principalmente no que se refere à manifestação da autoridade dos pais para o estabelecimento de normas e limites no comportamento infantil. As famílias foram caracterizadas pelos profissionais como multiproblemáticas (com múltiplas dificuldades) e multiassistidas (assistidas por diferentes serviços de apoio social). Apesar de caracterizarem as famílias como multiassistidas, alguns profissionais ressaltam que estas precisam de ajuda e de apoio para superar os conflitos. "Muitos problemas sem resolução. Precisa de incentivo para organizar a vida, principalmente das crianças" (relato de profissional - Carta de Encaminhamento no 11). Os motivos apontados pelos profissionais revelam que as famílias indicadas vivenciam situações de risco familiar e social e necessitam de auxílio educativo, para além do que já recebiam dos serviços especializados.

Dentre as 35 famílias que aderiram ao programa, a maioria foi representada pela participação de mulheres (30 participantes) e destas 25 foram representadas pela figura da mãe. Cabe ressaltar que todos os membros da família foram convidados a participar do programa, o que inclui homens, mulheres e crianças. A alta participação da mulher confirma que as mulheres ainda carregam as marcas históricas e culturais do cuidado familiar como uma atribuição feminina e como função relacionada à maternidade. Outro fator que explica a maior participação das mães é o fato de que as famílias participantes apresentam em sua maioria uma configuração ou estrutura familiar diferente da nuclear tradicional. Das famílias participantes, 13 apresentavam a configuração tradicional (pai, mãe e filhos), 16 eram monoparentais (apenas um adulto responsável, dos quais 12 eram mulheres/mães) e seis reconstituídas (famílias recasadas, com um integrante representado pelo padrasto ou madrasta).

Uma característica identificada nas famílias encaminhadas foi o elevado número de filhos. A maioria das famílias participantes possuía três filhos ou mais. Algumas destas tinham até oito filhos. Apesar de ser esta uma característica ainda muito presente em famílias de baixa renda brasileiras, parece ser relevante a reflexão sobre o fato de que esse aspecto (na percepção dos profissionais) era definidor para a escolha de famílias participantes do programa de educação parental como indicador de risco. Poucos agentes relevam a baixa eficiência de políticas públicas direcionadas ao planejamento familiar. Portanto, deve-se ressaltar que o contexto em famílias de classes populares é dinâmico e complexo. Por isso é importante considerar as influências das condições socioeconômicas e a pluralidade de formas de organização e configurações familiares, que se diferenciam dos padrões sociais e culturais construídos historicamente pelos discursos regulatórios e discriminantes.

\section{Facilitadores para o desenvolvimento do programa}

Como elementos facilitadores para a implementação do programa, ou seja, que aspectos podem contribuir para a realização deste, foram observadas as condições que devem atender a uma população bastante específica. Os facilitadores neste estudo são representados pelo suporte da rede de apoio social, pelas estratégias de organização dos encontros e pelo apoio oferecido para a presença das crianças. Essas estratégias de implementação das ações e de adesão das famílias no programa de educação parental estão diretamente vinculadas às possibilidades de organização e gerenciamento das ações, e precisam estar adaptadas à realidade do contexto no qual será aplicado o programa. Sendo assim, a equipe de educadores do programa, no Brasil, elaborou alternativas para que a proposta pudesse ser realizada com sucesso em contexto brasileiro.

\section{a) Encaminhamento das famílias pelos serviços da rede social}

Os serviços de apoio social acolheram a proposta e aceitaram a parceria na realização do programa de educação familiar. A parceria com os profissionais que integram a rede de apoio social mostrou-se uma estratégia importante para facilitar a indicação e o encaminhamento dos participantes para o programa de educação parental.

As famílias foram indicadas pelas escolas (12 famílias), pelas ONGs (13 famílias), pelas Equipes de Saúde da Família (10 famílias), pela Equipe Técnica das Instituições de Acolhimento (três famílias) e apenas uma pelos Conselhos Tutelares. Das 35 famílias que aderiram ao programa, quatro foram encaminhadas por mais de um serviço de apoio social.

O Conselho Tutelar foi o serviço com menor número de encaminhamentos e adesão das famílias participantes. Ao que tudo indica, esse serviço ainda carrega o discurso histórico da regulação e do controle sobre as atitudes parentais, o que pode ter prejudicado a abordagem e o convite às famílias para participarem do programa.

\section{b) Acesso e acolhimento dos participantes}

Para facilitar o acesso das famílias ao programa de educação parental, os encontros foram realizados nas localidades habitadas pelos participantes, ou seja, três bairros periféricos do município. Inicialmente, a equipe teve dificuldades com a cedência do espaço pelas escolas e pelos demais serviços da comunidade. Ao longo dos encontros, outros problemas com os locais foram apresentados: o trânsito e a permanência de outras 
pessoas no meio das sessões do programa; a dificuldade de deslocamento dos participantes nos dias de chuva e, até mesmo, o aviso sobre a impossibilidade de empréstimo do local dias antes do encontro.

Outra dificuldade enfrentada na implementação do programa foi a falta de recursos para o transporte de famílias de outras localidades. As famílias que aderiram ao programa e que moravam distantes do local pagavam as despesas de deslocamento ou caminhavam longa distância. Tais fatos demonstram as dificuldades práticas e o esforço que a participação comunitária em um programa social requer das pessoas que necessitam de atenção especial em nosso país.

Uma estratégia utilizada para o acolhimento dos grupos familiares nos encontros foi um lanche oferecido em todos os grupos ao final do encontro. No entanto, cabe ressaltar que não foram oferecidas recompensas às famílias pela sua participação nos encontros, ou seja, os participantes não receberam brindes ou prêmios em troca da presença no programa.

\section{c) Cuidado e apoio educativo às crianças durante os encontros}

Tendo como objetivo realizar uma intervenção educativa com a família, e não somente com os pais e/ou responsáveis, foi criada a estratégia para o atendimento educativo das crianças. Esta não estava prevista pelo Programa "Crescer Felizes em Família" realizado na Europa e origina-se de outras experiências de educação familiar do grupo de pesquisa que o aplicou. Como os filhos acompanhavam os pais aos atendimentos, pareceu necessário realizar um trabalho paralelo com as crianças. Além disso, é importante realizar a oitiva e compreender a perspectiva das crianças sobre as relações e práticas educativas familiares.

Sendo assim, participaram aproximadamente 33 crianças: 18 meninos e 15 meninas de 0 a 12 anos que integravam as famílias indicadas para o programa. Destas, 10 participaram do programa de educação parental realizado na escola, 10 na ONG e 13 no centro comunitário. Para cada localidade, um grupo de acadêmicos ficou responsável por formular e aplicar atividades pedagógicas para as crianças. Estas consideraram os interesses das crianças, as temáticas abordadas no programa de educação parental e a possibilidade de expressão das crianças sobre as suas vivências no ambiente familiar.

\section{Satisfação e eficácia do programa de educação parental}

A partir das avaliações realizadas pelas famílias participantes do programa, procurou-se identificar e avaliar a satisfação (ou não) com os aspectos que caracterizavam o desenvolvimento das intervenções e a possível eficácia dos mesmos no processo de formação dos participantes.

Os resultados obtidos permitem afirmar que a proposta, de maneira global, foi satisfatória para as famílias. Na sequência são apresentados os principais fatores avaliados pelas famílias participantes.

\section{a) Os conteúdos e assuntos abordados no programa}

Considerados adequados às situações vivenciadas pelos participantes, os conteúdos contribuíram para a discussão das práticas educativas e dos estilos parentais. Quando questionados sobre o que mais gostaram do programa, as famílias responderam que foi importante aprender a conhecer os filhos (Módulo 2) e a estabelecer limites para o comportamento infantil (Módulo 3). "Gostei de ter compreendido a maneira que meu filho é" (família participante). "Gostei de aprender os limites de mãe e filho" (família participante).

As atividades propostas pelos módulos temáticos se mostraram adequadas diante das situações evidenciadas pelas famílias participantes, contribuíram para ampliar os relatos sobre as práticas educativas parentais e possibilitaram a reflexão sobre a educação no ambiente familiar. A maioria das famílias demonstrou a necessidade de relatar as suas vivências e dificuldades na educação das crianças, bem como interesse em repensar e aprender novas estratégias educativas. "Todas as partes foram úteis para mim para minhas atitudes com minhas filhas" (família participante). "A parte mais útil do programa foi como educar as crianças, sugestões de como fazer" (família participante). As práticas parentais geradas pelo "compromisso" firmado nos encontros apresentaram resultado positivo nas famílias mais interessadas no programa e dedicadas a buscar alternativas para melhorar as práticas educativas com os filhos. "Ao final de nossa conversa, a Paula assumiu um compromisso com o grupo, que iria parar um dia, e com calma e sem ter pressa, ela iria brincar de bonecas com as meninas" (diário do grupo de pesquisa). "Paula chegou atrasada e nos relatou que cumpriu o compromisso assumido com o grupo no encontro anterior. Disse que foi muito bom e pelo que pudemos perceber ela se divertiu mais que as filhas" (diário do grupo de pesquisa). Essa situaçãoexemplo demonstra que a mãe estava preocupada em interagir mais com as filhas e queria estar mais atenta à relação entre as irmãs, que estavam constantemente brigando e disputando a atenção da mãe. O relato da mãe aponta para uma solução "simples" para o problema vivenciado e para uma prática educativa parental que pode melhorar o cotidiano das interações familiares. 


\section{b) As interações no grupo}

Interações entre os participantes e destes com a equipe de dinamizadores/ mediadores foram percebidas como potencializadoras de vínculos e de sentimentos de confiança entre as famílias participantes e destas com a equipe de dinamizadores. "O que mais gostei nesse programa foi do grupo, do relacionamento com a equipe, sempre vinha gente nova. Gostei das famílias que participaram, embora poucas tenham ficado" (família participante).

Na percepção das famílias participantes, os dinamizadores/ mediadores têm um papel importante que pode colaborar para o bem-estar do grupo e motivar relatos (desabafos) e reflexões dos participantes. Foi referido que os mesmos demonstravam respeito pelas opiniões dos participantes e interesse pelos "problemas" narrados. "O que mais gostei foi poder desabafar, ter alguém para me escutar" (família participante). "Gostei da oportunidade de a gente ser sincero. Que a equipe ajudou a gente" (família participante). "Gostei do grupo, do relacionamento com a equipe" (família participante). O apoio grupal para a partilha de experiências é um princípio relevante para o fortalecimento da parentalidade positiva, de acordo com o modelo experiencial, e foi um dos aspectos mais destacados na avaliação de satisfação das famílias participantes.

\section{c) Impacto do programa}

A avaliação aponta o impacto do programa nas práticas parentais a partir dos seguintes elementos:

- Afirmativas dos pais acerca da melhor compreensão de seus filhos. Em diferentes momentos, alegavam pensar mais nas dificuldades das relações, nos temas abordados nas sessões e nas possíveis alternativas para solucionar os problemas. De acordo com o relato de uma das famílias participantes, o programa foi útil para "a percepção que passei a ter como mãe. Agora penso diferente, podendo entender melhor as dificuldades dos meus filhos. Passei a entender a importância de dizer 'não' a eles" (família participante). Essa fala atesta que um dos objetivos fundamentais do programa foi atingido, qual seja, provocar a reflexão sobre a importância do comportamento dos pais no desenvolvimento dos filhos (RODRIGO et al., 2008b).

- Fortalecimento e alterações das práticas parentais. Deve-se ressaltar que, entretanto, verificaram-se influências menos significativas no comportamento das crianças. Uma das famílias participantes sugeriu que as educadoras "conversassem mais com as crianças" (família participante).
- Satisfação sobre sua participação no programa, sendo ressaltado pelas famílias participantes que elas o recomendariam a outros grupos familiares.

- Manifestações claras sobre a necessidade de o programa continuar e de estipular mais tempo para a realização das sessões.

\section{DISCUSSÃO}

A partir da análise das falas e manifestações dos participantes, foi possível identificar elementos de avaliação e satisfação sobre o desenvolvimento do programa "Crescer Felizes em Família" no Brasil. Embora as famílias participantes fossem consideradas "em situação de risco" e, em alguns casos, houvesse a necessidade de um atendimento individualizado, a proposta grupal foi satisfatória para as mesmas, principalmente no que se refere aos conteúdos, à interação e ao apoio prestado pelo grupo.

Na maioria das famílias, ficou claro que o programa teve um impacto significativo na função parental, estimulando-as a "pensar nas sessões" ao se defrontar com a necessidade de resolução de um problema/dificuldade. Assim, as famílias tornaram-se/sentiam-se mais capazes, e talvez mais apoiadas e acompanhadas para buscar e arquitetar melhores soluções para a educação das crianças.

Ademais, as discussões temáticas e as atividades propostas pelos módulos temáticos se mostraram adequadas para trabalhar reflexivamente as situações evidenciadas pelas famílias participantes, pois contribuíram para ampliar os relatos sobre as práticas educativas parentais e possibilitaram pensar mais profundamente sobre a educação no ambiente familiar. A maioria das famílias demonstrou a necessidade de compartilhar o relato das suas vivências e dificuldades na educação das crianças, bem como um grande interesse em repensar e aprender novas estratégias educativas.

Algumas singularidades da aplicação de estratégias no contexto brasileiro para aumentar o envolvimento dos pais na dinâmica das sessões referem-se ao analfabetismo ou às dificuldades de interpretação da maioria participantes, devido à baixa escolaridade. Mesmo os que sabiam ler, pediam auxílio para a leitura das atividades e para o preenchimento do questionário de avaliação. Porém, elementos constitutivos desse programa, como a ilustração das atividades e o incentivo às narrativas $\mathrm{e}$ ao diálogo, minimizaram as limitações demonstradas pelos participantes. Em um país como o Brasil, com índices ainda preocupantes de analfabetismo, esta é uma dimensão estratégica importante a ser relevada por programas públicos de educação popular.

O diálogo e o atendimento individual foram estratégias fundamentais para estabelecer vínculos e construir 
relações de confiança entre os integrantes dos grupos do programa. Tais estratégias, que constituem a tônica da metodologia experiencial, garantiram a dinâmica dos encontros e a participação efetiva dos integrantes nas atividades propostas. As narrativas dos participantes sobre as práticas foram consideradas para a discussão sobre as temáticas. Com a intervenção dos educadores/ dinamizadores foi possível discutir as experiências narradas e ampliar o repertório sobre o tema em questão. A relação dialógica entre os educadores/dinamizadores e as famílias, construída nos encontros, propiciou uma integração e vinculação entre os participantes.

A adesão e participação das famílias foi o maior desafio enfrentado na aplicação do programa de educação parental em contexto brasileiro. Houve problemas com a falta de assiduidade aos encontros por parte de algumas famílias que aderiram ao programa. Os motivos da não adesão ou da infrequência de alguns participantes no programa foram identificados pelos profissionais e expressos por algumas famílias desta forma: compreender a proposta educativa - parecia persistir no imaginário as noções de fiscalização e intervenção no ambiente familiar; acessar o local dos encontros; adequar-se os horários dos encontros à rotina de trabalho; comprometer-se e ter assiduidade aos encontros; compartilhar e expor ao grupo as suas próprias situações de adversidade.

Já a maior dificuldade na participação das famílias foi constatada no espaço escolar. As famílias demonstraram uma resistência maior em aceitar os encontros, sendo que algumas confirmavam a adesão ao programa no primeiro encontro, mas não compareciam nos posteriores. No contexto da escola, apenas três famílias foram frequentes aos encontros.

A participação das famílias no ambiente escolar é motivo de debate e preocupações por parte dos profissionais da educação. É fato que o relacionamento entre escola e família pode colaborar para o desenvolvimento infantil, através de interações mesossistêmicas de comunicação recíproca, apoio e colaboração na educação das crianças (BRONFENBRENNER, 1996). Ao saber disto, os professores, por vezes, parecem angustiados com a falta de participação e parceria de alguns pais e/ou responsáveis na escola. Mas quais os mecanismos que são utilizados para a participação da família na escola? A participação "é um processo de conquista" (DEMO, 1988) e, por isso, é preciso aprofundar a discussão e construir estratégias de participação, ao invés de culpabilizar a família por não estar cumprindo o seu papel de parceira.

Outro aspecto a se destacar diz respeito ao perfil dos participantes no programa desenvolvido no Brasil. As famílias encaminhadas pelos profissionais apresentavam um perfil definido pelas condições sociais e situações de risco comuns, determinando a composição bastante homogênea dos grupos de educação parental. Essa situação, contrária à proposta inicial dos programas de educação parental presente na recomendação da ChildONEurope (2007), é ainda um sério impeditivo para que as intervenções se entendam como um direito de apoio de todas as famílias indistintamente. E não somente direcionado às famílias em situação de pobreza ou que vivenciem situações de alto risco para o desenvolvimento infantil. Formar grupos de apoio parental heterogêneos, ou seja, reunidos a partir do convite ou indicação de diferentes famílias que apresentam modos diversos de organização, configuração, nível de escolaridade, situação financeira, é essencial para esse desígnio.

A avaliação do programa de origem espanhola realizado no Brasil apontou para o importante apoio grupal e para a possibilidade de empoderamento de pais e cuidadores com promoção da resiliência parental em famílias consideradas em situação de risco pelos profissionais da rede social. No que se refere ao funcionamento e à satisfação das famílias, os resultados revelam a importância do acolhimento, e as interações significativas em grupos de apoio contribuíram para a participação e satisfação revelada pelos grupos familiares. Apesar da importância da existência de um manual com as instruções para estabelecer uma padronização na aplicação do programa parental, não há como sistematizar a sensibilidade e a flexibilidade na postura dos educadores na relação com os participantes e no desenvolvimento da proposta. Sem dúvida, esses elementos são fundamentais para a satisfação dos participantes e eficácia da proposta (ALMEIDA et al., 2012). Os processos proximais construídos nos grupos de apoio se apresentaram como importantes motores para o desenvolvimento e aprendizado de todos os integrantes desse grupo (BRONFENBRENNER, 1996).

Os resultados descritos por este artigo apontaram as possibilidades, os limites e as dificuldades na aplicação de programas de educação parental em diferentes contextos culturais e sociais. Esses aspectos foram evidenciados a partir da análise de categorias como a dinâmica do programa, o papel dos facilitadores e a satisfação pelos participantes do programa "Crescer Felizes em Família" no Brasil. De acordo com Bronfenbrenner (1996), as dimensões macrossistêmicas, como a cultura, influenciam as interações meso e microssistêmicas do contexto familiar. O contexto brasileiro, sobre o qual se pautam as considerações deste artigo, permitiu reconhecer o modo como a raiz cultural dialoga com as condições sociais, com os modos de convívio e com a estrutura social nas suas especificidades. Em termos macrossistêmicos, a análise das políticas públicas direcionadas para as famílias nesse contexto apontam para a necessidade de medidas de apoio educativo, cuja oferta e abrangência é ainda restrita diante da demanda social. 


\section{CONSIDERAÇõeS FINAIS}

A partir do estudo realizado sobre a aplicabilidade do programa "Crescer Felizes em Família" no Brasil, pode-se afirmar que é possível a realização de programas de educação parental em contextos caracterizados pela situação de pobreza e vulnerabilidade das famílias. Porém algumas estratégias que envolvem a dinâmica de funcionamento desse programa precisam ser adequadas à realidade local. Tendo em vista os resultados que emergiram dessa experiência, foi possível constatar que algumas das condições socioculturais e organizacionais para a elaboração, execução e avaliação de programas no Brasil são expressas pelas seguintes necessidades: elaboração dos mecanismos de divulgação da proposta para a melhor compreensão e adesão das famílias no programa; integração das ações em educação parental às políticas públicas municipais para a garantia do suporte dos profissionais dos serviços sociais e para o auxílio à logística de implementação do programa; definição do calendário e horários dos encontros de acordo com as preferências do grupo; ampliação do tempo das atividades nas sessões; e adequação das atividades escritas de acordo com o público do programa.

O programa "Crescer Felizes em família", realizado sob a ótica da metodologia experiencial e do modelo reflexivo, esteve de acordo com a perspectiva da mediação dialógica muito utilizada no trabalho com grupos educativos em pedagogia social. De acordo com Carvalho e Baptista (2004), a mediação pedagógica na pedagogia social deve, além da prevenção e negociação de conflitos, "promover relações interpessoais positivas, impulsionadoras de atividade, de criatividade e de solidariedade" (p. 72). Essa proposta educativa pode caracterizar um avanço acerca da perspectiva em educação parental, ao não limitar-seapenas às influências das relações intrafamiliares e ao considerar como fundamentais outros elementos significativos, como as relações das famílias com outros contextos ecológicos de desenvolvimento humano (por exemplo, relação família e escola). Diante disso, a promoção da educação social com famílias, a abordagem sistêmica dos conteúdos e o uso de metodologias que tenham como base o diálogo e o respeito às diferenças são características apontadas como relevantes para a aplicabilidade de programas de educação parental em contexto brasileiro.

As dificuldades na função parental e os conflitos intrafamiliares são percebidos, na maioria das vezes, como problemas de origem pessoal e pouco se remeteriam aos serviços sociais e políticas públicas. No entanto, ao nos depararmos com uma sociedade contemporânea capitalista e consumista, com os agravantes da negligência e violência doméstica contra crianças e adolescentes, é preciso compreender que a família se constitui como o primeiro contexto de educação e de formação das representações sociais, e, por isso, pode contribuir para que os vínculos de afeto, solidariedade e cuidado sejam fortalecidos entre as pessoas. Nesse sentido, é preciso problematizar o binômio público versus privado no que se refere às relações familiares, ampliar a perspectiva sobre o impacto social das práticas parentais como potencializadoras (ou não) de desenvolvimento humano e comunitário, e promover a continuidade dos estudos da pedagogia social com famílias no campo das ciências da educação.

\section{REFERÊNCIAS}

ALMEIDA, Ana Maria Tomás et al. Avaliação da satisfação e eficácia do programa de formação parental (versão para pais). Instrumento de pesquisa impresso. Universidade do Minho, Portugal, 2008.

ALMEIDA, Ana Maria Tomás et al. Parent education interventions: results from a national study in Portugal. European Journal of Developmental Psychology, London, v. 9 , n. 1, p.135-149, 2012. http://dx.doi.org/10.1080/174056 29.2011.647865

BRONFENBRENNER, Urie. A ecologia do desenvolvimento humano: experimentos naturais e planejados. Porto Alegre: Artes Médicas, 1996.

CARVALHO, Adalberto Dias de; BAPTISTA, Isabel. Educação social: fundamentos e estratégias. Porto, Portugal: Porto Editora, 2004. (Coleção Educação e Trabalho Social, 01).

CECCONELLO, Alessandra Marques; KOLLER, Silvia Helena. Inserção ecológica na comunidade: uma proposta metodológica para o estudo de famílias em situação de risco. In: KOLLER, Silvia Helena (Org.). Ecologia do desenvolvimento humano: pesquisa e intervenção no Brasil. São Paulo: Casa do Psicólogo, 2004. p. 267-292.

CHARMAZ, Kathy. A construção da teoria fundamentada. Porto Alegre: Artmed, 2009.

CHILDONEUROPE. Survey on the role of parents and support from the governments in the EU. Strasbourg, France: Council of Europe Publications, 2007.

SAMPAIO, Daniel; CRUZ, Hugo; CARVALHO, Maria. Crianças e jovens em risco: a família no centro da intervenção. Cascais, Portugal: Princípia, 2011.

DEMO, Pedro. Participação é conquista: noções de política participativa. 3. ed. São Paulo: Cortez, 1996.

GARCIA, Narjara Mendes. Educação parental: estratégias de intervenção protetiva e as interfaces com a Educação Ambiental. Tese (Doutorado em Educação Ambiental) - Universidade Federal do Rio Grande, Rio Grande, 2012.

HEATH, Harriet. Assessing and delivery parent support. In: HOGHUGHI, Masud; LONG, Nicholas (Ed.). Handbook of parenting: theory and research for practice. London: British Library, 2004.

PRATI, Larissa et al. Revisando a inserção ecológica: uma proposta de sistematização. Psicologia: Reflexão e Crítica, Porto Alegre, v. 21, n. 1, p.160-169, 2008. 
QUINTANA, Juan Carlos Martín et al. Programas de educación parental. Intervención Psicosocial, Madrid, v. 18, n. 2, p. 121-133, 2009.

QUINTANA, Juan Carlos Martín; LÓPEZ, Maria José Rodrigo, 2013. La Promoción de la parentalidad positiva. Revista Educação, Ciência e Cultura, UnilaSalle, Canoas, v. 18, n. 1, p. 77-78, jan./jun. 2013.

RODRIGO, Maria José et al. Preservación familiar: um enfoque positivo para la intervención com famílias. Madrid, Espanha: Ediciones Pirámide, 2008a.
RODRIGO, Maria José et al. Crecer felices en família: um programa de apoyo psicoeducativo para promover el desarrollo infantil. Canarias, Espanha: Dirección General de Acción Social, Consejería de Sanidad y Bienestar Social, Junta de Castilha y León, 2008b.

SERRANO, Glória Pérez. Elaboração de projectos sociais: casos práticos. Porto: Porto Editora, 2008.

Submetido em: 22/07/2015

Aprovado em: 18/12/2015 